Original Research Paper

\title{
Diversity of Butterfly (Rhopalocera) in The River Flow Area at Taman Hutan Raya Sesaot as an Enrichment of Animal Ecology Practicum Materials
}

\author{
Rawindy Aulia Hapsari ${ }^{1 *}$, Agil Al Idrus ${ }^{1}$, Mohammad Liwa Ilhamdi ${ }^{1}$ \\ ${ }^{1}$ Department of Biology Education, University of Mataram, Mataram, Indonesia
}

\author{
Article History \\ Received : November $16^{\text {th }}, 2021$ \\ Revised : December 20 ${ }^{\text {th }}, 2021$ \\ Accepted : December 29 $9^{\text {th }}, 2021$ \\ Published : January $12^{\text {th }}, 2022$ \\ *Corresponding Author: \\ Rawindy Aulia Hapsari, \\ ${ }^{1}$ Department of Biology \\ Education, University of \\ Mataram, Mataram, Indonesia; \\ Email: windy36ixh@gmail.com
}

\begin{abstract}
The butterfly is one of the insects type that originated from the order of lepidoptera, which having scaly wings. The scales is what gives pattern on the butterflies' wings. In ecosystems, butterflies serves as a pollinator that helps plants to reproduce. Besides, butterflies like the environment that is close to the river flow. Thus allowing the possibility of butterflies activities in the surrounding area over the river flow at Taman Hutan Raya Sesaot. The research is aimed to identify species of butterflies (suborder Rhopalocera) and to determine the level of diversity of butterflies in the river flow areas at Taman Hutan Raya Sesaot. This research is carried out from January until February 2021 in the river flow area at Taman Hutan Raya Sesaot. Conducted in three points, namely the path of water 1 , the path skirting the woods and pathways of water 2 . The methods of taking samples of butterflies conducted by purposive survey method. The mechanical technic of taking samples is done by using nets insects. Analysis of butterfly diversity index obtained diversity index $\left(\mathrm{H}^{\prime}\right)$ and index of dominance (D). Analysis of butterfly diversity index obtained diversity index (H') for all species, namely 2.29 (medium category). Analysis index of dominance obtained index of dominance for the entire species, namely 0.13 (relatively low). Based on the results of the research, the writer found 16 species (164 individuals) that were included into the four families of Papilionidae, Nymphalidae, Pieridae and Lycaenidae.
\end{abstract}

Keywords: Butterfly, Diversity, Dominance, Sesaot Forest.

\section{Pendahuluan}

Indonesia sering disebut sebagai negara megabiodiverity karena memiliki keanekaragaman hayati yang tinggi dimana terdapat jenis tumbuhan dan hewan yang melimpah yang dapat ditemukan di Indonesia. Menurut Darajati et al., (2016), keanekaragaman hayati adalah semua makhluk hidup yang ada di bumi, termasuk semua jenis tumbuhan, hewan, dan mikroba. Keanekaragaman hayati saling berhubungan dan membutuhkan satu sama lain untuk tumbuh dan berkembang biak sehingga membentuk suatu sistem kehidupan.

Salah satu keanekaragaman hayati di Indonesia adalah kelompok serangga. Serangga (insekta) adalah kelompok hewan dengan jumlah spesies terbanyak yaitu $3 / 4$ dari seluruh spesies hewan yang ada di bumi. Insekta terdata paling banyak spesiesnya adalah kumbang dan kupukupu, karena dipengaruhi oleh tersedianya tanaman inang sebagai sumber energi dalam bentuk makanan (Tarumingkeng, 2001).

Kupu-kupu merupakan kelompok serangga yang masuk dalam Ordo Lepidoptera yang berarti mempunyai sayap bersisik. Sisik inilah yang memberi corak dan warna pada sayap kupu-kupu (Wahyuni dan Fatahullah, 2015). Kupu-kupu adalah salah satu serangga yang paling dikenal dan paling populer (Picker et al., 2004). Hanya sebagian kecil dari kupu-kupu (sekitar $10 \%$ ) dari 170.000 jenis Lepidoptera yang ada di dunia. Bagian terbesarnya adalah ngengat. Kupu-kupu memiliki jumlah jenis yang lebih sedikit dari ngengat, namun kupu-kupu lebih dikenal karena sifatnya yang diurnal (aktif pada siang hari) dan 
memiliki warna yang cerah serta menarik (Peggie dan Amir, 2006).

Kupu-kupu juga memiliki peranan dalam ekosistem, yaitu sebagai pollinator yang membantu terjadinya penyerbukan pada tumbuhan yang tidak dapat melakukan penyerbukan sendiri. Keberadaan dan peranan inilah yang mendukung alasan pentingnya pelestarian kupu-kupu. Selain itu, kupu-kupu juga dikenal sebagai satwa yang memiliki nilai ekonomi tinggi, yaitu sebagai objek rekreasi dan satwa koleksi. Warna dan bentuk sayapnya yang indah merupakan pesona dan memiliki daya tarik tersendiri yang mampu memikat hati banyak orang (Syaputra, 2015).

Kupu-kupu aktif mencari makan pada pagi hari, pada siang hari serangga ini lebih banyak beristirahat diantara dedaunan untuk menghindari suhu lingkungan yang tinggi (Syaputra, 2015). Kupu-kupu dewasa mencari nutrisi tambahan berupa mineral dan nutrisi dari kotoran satwa maupun sisa-sisa buah-buahan busuk di sepanjang aliran sungai. Kupu-kupu sangat menyukai lingkungan yang dekat dengan air atau di sekitar aliran sungai, sehingga memungkinkan adanya aktivitas kupu-kupu pada Daerah Aliran Sungai (DAS) Taman Hutan Raya Sesaot.

Hutan Raya Sesaot terletak di Kecamatan Narmada dan Lingsar, Kabupaten Lombok Barat dan diapit oleh empat desa, yaitu Sesaot, Lebah Sempage, Sedau, dan Batu Mekar (Galudra et al., 2010). Hutan ini memiliki luas $5.950,18 \mathrm{Ha}$ dan merupakan daerah tangkapan air dari DAS Dodokan. Fungsi kawasan hutan lindung Sesaot telah diubah menjadi Taman Hutan Raya (Tahura) dengan surat keputusan Menteri Kehutanan dan Perkebunan No. 244/Kpts-II/99 tanggal 27 April 1999 dengan luas +- 3.155 Ha yang terletak di Desa Sesaot, Kecamatan Narmada, Kabupaten Lombok Barat, Provinsi Nusa Tenggara Barat. Taman Hutan Raya (Tahura) Sesaot juga memiliki banyak pesona alam yang sangat indah, sehingga menjadi salah satu tujuan destinasi wisata.

Penelitian tentang keanekaragaman kupukupu di beberapa daerah di Indonesia telah banyak dilakukan. Penelitian yang pernah dilakukan oleh Wahyuni dan Fatahullah (2015) diperoleh sekitar 41 jenis kupu-kupu dari 3 famili dan terdapat salah satu spesies kupu-kupu yang dilindungi di Indonesia yaitu Troides helena. Juarni (2017) mencatat 13 jenis kupu-kupu dari 5 famili.
Penelitian yang dilakukan oleh Juarni (2017) di kawasan Taman Hutan Raya Sesaot juga dilakukan di Hutan Wisata Aik Berik Sedangkan peneliti hanya memilih lokasi penelitian di kawasan Taman Hutan Raya Sesaot karena belum pernah di dokumentasikan, Taman Hutan Raya (Tahura) Sesaot perlu memiliki data keanekaragaman kupu-kupu untuk mengetahui keanekaragamannya (subordo Rhopalocera) sebagai pengayaan materi praktikum ekologi hewan.

\section{Bahan dan Metode}

Jenis penelitian ini adalah penelitian deskriptif eksploratif. Pendekatan yang digunakan dalam penelitian ini adalah pengamatan secara langsung di lapangan dan laboratorium untuk memperoleh gambaran tentang keanekaragaman kupu-kupu di Hutan Raya Sesaot.

Penelitian ini dilakukan pada bulan JanuariFebruari 2021 di Daerah Aliran Sungai (DAS) Taman Hutan Raya (Tahura) Sesaot Lombok Barat, Provinsi Nusa Tenggara Barat. Proses pengambilan data dalam penelitian ini menggunakan metode survei secara purposive sampling. Penangkapan kupu-kupu dilakukan dengan menggunakan jaring serangga dengan mengikuti jalur pengamatan yaitu jalur air 1, hutan, dan jalur air 2.

Pengambilan data kupu-kupu dilakukan dengan metode survei. Penangkapan kupu-kupu dilakukan dengan menggunakan teknik sweeping dengan mengikuti jalur transek yang telah ditentukan. Jenis kupu-kupu yang belum teridentifikasi, dimasukkan ke dalam kertas papilot. Setiap kertas papilot yang di dalamnya terdapat spesies kupu-kupu diberi kode abjad atau angka untuk membedakan spesies yang satu dengan yang lainnya. Kupu-kupu yang telah dimasukkan ke dalam kertas papilot dimasukkan ke dalam kotak koleksi agar tidak rusak atau patah. Setelah itu sampel yang didapat dibawa ke laboratorium untuk dibuat spesimen keringnya selanjutnya diidentifikasi menggunakan buku identifikasi kupu-kupu.

Kupu-kupu ditangkap menggunakan jaring serangga. Pengkoleksian kupu-kupu dilakukan dari jam 07.00-17.00 yang dilakukan 1 kali dalam seminggu selama 4 minggu. Pemilihan waktu penelitian berdasarkan waktu aktifnya kupu-kupu (Ariani, 2013). Sampel kupu-kupu yang ditangkap di 
lapangan diawetkan dengan cara menyuntikkan larutan formalin $4 \%$ di bagian thoraknya menggunakan alat suntik. Sayap kupu-kupu tersebut dibentangkan segera setelah disuntik dan dimasukkan dalam kertas papilot.

Data hasil pengamatan kupu-kupu yang diperoleh kemudian dianalisis secara kuantitatif yang meliputi indeks keanekaragaman jenis dan dominansi spesies dengan rumus:

Indeks Keanekaragaman (Shannon-Wiener)

Dimana:

$$
\mathrm{H}^{\prime}=-\sum_{\mathrm{i}=1}^{\mathrm{s}} \mathrm{Pi} \ln \mathrm{Pi}
$$

H': Indeks keanekaragaman jenis

ni : Jumlah individu jenis ke-i

$\mathrm{N}$ : Jumlah individu seluruh jenis (Magurran, 2004)

\section{Indeks dominansi Simpson}

Nilai indeks dominansi di dalam suatu komunitas dapat diketahui dengan menggunakan indeks dominansi Simpson, yaitu:

$$
\mathrm{D}=\sum_{i=0}^{s} P i^{\wedge} 2
$$

D : Indeks Dominansi

ni : Jumlah individu spesies ke-i

N : Jumlah total individu (Magurran, 2004).

\section{Hasil dan Pembahasan}

\section{Keanekaragaman Jenis Kupu-kupu (Rhopalocera)}

Penelitian keanekaragaman kupu-kupu (Rhopalocera) di Daerah Aliran Sungai (DAS) Taman Hutan Raya Sesaot meliputi 3 jalur pengamatan, yaitu jalur sungai 1 , jalur sungai 2 , dan daerah hutan. Data jumlah spesies yang tertangkap dalam jaring dapat dilihat pada Tabel 1 . Spesiesspesies yang tertangkap dalam jaring tidak hanya dari subordo Rhopalocera (kupu-kupu siang) melainkan subordo Heterocera (ngengat) dan subordo odonata (capung) juga tertangkap dalam jaring. Subordo Heterocera yang tercuplik yaitu family Noctuidae sedangkan subordo odonata yang tercuplik family Libellulidae terdapat 2 spesies yang tertangkap dalam jaring.

Jumlah total kupu-kupu yang tercatat di seluruh jalur pengamatan sebanyak 164 individu, terdiri atas 16 spesies dari 4 famili yang termasuk dalam subordo Rhopalocera, seperti yang terlihat pada Tabel 1.

Tabel 1. Spesies Kupu-kupu (subordo Rhopalocera) di Daerah Aliran Sungai (DAS) Taman Hutan Raya

\begin{tabular}{|c|c|c|c|c|c|c|}
\hline \multirow{3}{*}{ No } & \multirow{3}{*}{ Family } & \multirow{3}{*}{ Nama Spesies } & \multicolumn{3}{|c|}{ Lokasi } & \multirow{3}{*}{ Jumlah } \\
\hline & & & & ggir $\mathrm{Hu}$ & & \\
\hline & & & Jalur Air 1 & Sesaot & Jalur Air 2 & \\
\hline \multirow{4}{*}{1} & \multirow{4}{*}{ Papilionidae } & Papilio polytes & 1 & 0 & 1 & 2 \\
\hline & & Papilio demoleus linneus & 4 & 0 & 0 & 4 \\
\hline & & Papilio memnon & 5 & 13 & 7 & 25 \\
\hline & & Graphium sarpedon & 0 & 0 & 3 & 3 \\
\hline \multirow{7}{*}{2} & \multirow{7}{*}{ Nymphalidae } & Melanitis leda & 0 & 8 & 0 & 8 \\
\hline & & Junonia Athlites & 6 & 5 & 0 & 11 \\
\hline & & Mycalesis horsfildi & 11 & 2 & 0 & 13 \\
\hline & & Elymnias hypemnestra & 4 & 0 & 0 & 4 \\
\hline & & Hypolimnas bolina & 9 & 4 & 0 & 13 \\
\hline & & Nepthis hylas & 0 & 2 & 0 & 2 \\
\hline & & Ideopsis juventa & 0 & 2 & 0 & 2 \\
\hline \multirow{3}{*}{3} & \multirow{3}{*}{ Pieridae } & Letopsia nina & 15 & 16 & 8 & 39 \\
\hline & & Catopsila Pomana & 3 & 0 & 0 & 3 \\
\hline & & Eurema hecabe & 8 & 8 & 13 & 29 \\
\hline
\end{tabular}
Sesaot Famili/Spesies 


\begin{tabular}{|c|c|c|c|c|c|c|}
\hline \multirow{4}{*}{4} & & Eurema blanda & 0 & 4 & 0 & 4 \\
\hline & Lycanidae & Jamides bochus & 2 & 0 & 0 & 2 \\
\hline & & JUMLAH & 68 & 64 & 32 & 164 \\
\hline & & $\begin{array}{c}\text { H' Tiap jalur } \\
\text { H' Seluruh jenis }\end{array}$ & 2.1904138 & $\begin{array}{c}2.0608635 \\
2.29818456\end{array}$ & 1.3752021 & \\
\hline
\end{tabular}

Analisis indeks keanekaragaman seluruh jenis (H') di Daerah Aliran Sungai (DAS) Taman Hutan Raya Sesaot menunjukkan nilai 2,3 (Tabel 1). Berdasarkan indeks keanekaragaman jenis menurut Odum nilai indeks keanekaragaman jenis kupu-kupu di Daerah Aliran Sungai (DAS) Taman Hutan Raya Sesaot tergolong sedang. Odum (1993) mengklasifikasikan indeks keanekaragaman ini ke dalam tiga kategori yaitu rendah $\left(\mathrm{H}^{\prime}<2\right)$, sedang $\left(2,0<\mathrm{H}^{\prime}>3\right)$ dan tinggi $\left(\mathrm{H}^{\prime}>3\right)$, sedangkan analisis indeks keanekaragaman tiap jalur penelitian (Gambar 1) masing-masing menunjukkan nilai 2.19 jalur sungai 1, 2.06 jalur pinggir hutan sesaot, dan 1.37 jalur sungai 2 .

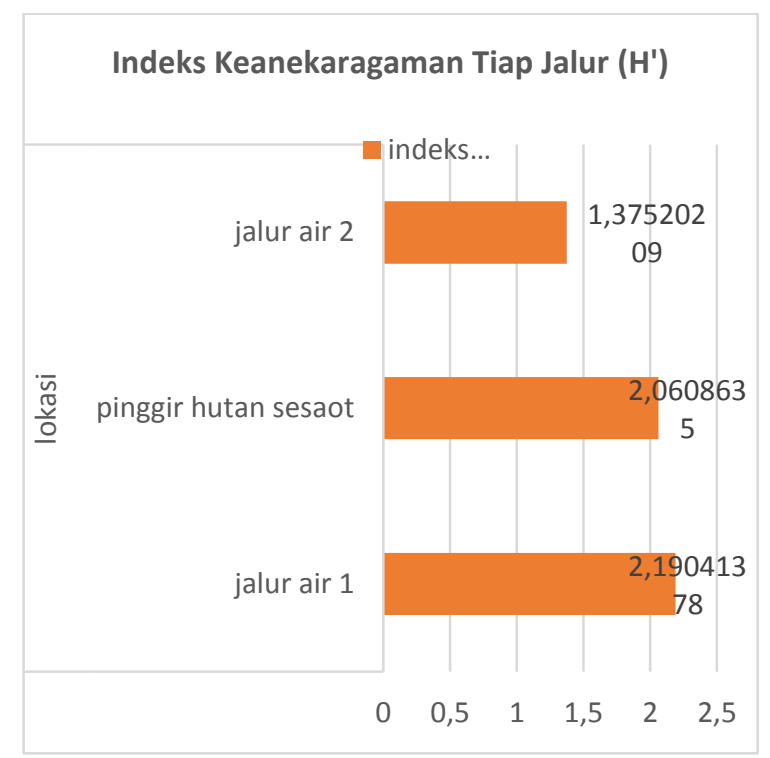

Gambar 1. Indeks indeks keanekaragaman tiap jalur penelitian

Pengamatan mengenai faktor lingkungan juga dilakukan untuk mengetahui kondisi lingkungan yang sesuai untuk habitat kupu-kupu. Kondisi lingkungan di Daerah Aliran Sungai (DAS) Taman Hutan Raya Sesaot disajikan pada Tabel 2.
Tabel 2. Kondisi Lingkungan DAS Taman Hutan

\begin{tabular}{|l|l|l|l|l|l|}
\hline No & $\begin{array}{l}\text { Faktor } \\
\text { lingkungan }\end{array}$ & $\begin{array}{l}\text { Jurnal } \\
\text { sungai } \\
1\end{array}$ & $\begin{array}{l}\text { Pinggir } \\
\text { Hutan } \\
\text { Sesaot }\end{array}$ & $\begin{array}{l}\text { Jurnal } \\
\text { Sungai } \\
2\end{array}$ & $\begin{array}{l}\text { Rata- } \\
\text { Rata }\end{array}$ \\
\hline 1 & Suhu & $24^{\circ} \mathrm{C}$ & $25^{\circ} \mathrm{C}$ & $24^{\circ} \mathrm{C}$ & $24,33^{\circ} \mathrm{C}$ \\
\hline 2 & $\begin{array}{l}\text { Kelembaban } \\
\text { Udara }\end{array}$ & $70 \%$ & $80 \%$ & $70 \%$ & $75 \%$ \\
\hline
\end{tabular}

Dominansi Jenis Kupu-kupu (Rhopalocera) di Daerah Aliran Sungai (DAS) Taman Hutan Raya Sesaot

Analisis indeks dominansi seluruh jenis (ID) di Daerah Aliran Sungai (DAS) Taman Hutan Raya Sesaot menunjukkan nilai 0.1335515 dan analisis indeks dominansi tiap jalur penelitian (Gambar 2) berikut ini.

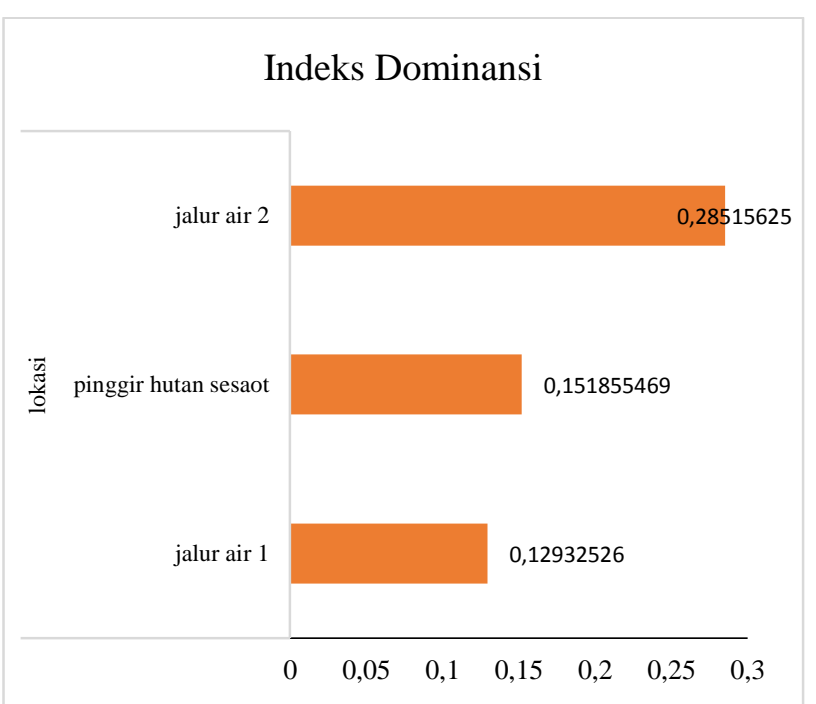

Gambar 2. Indeks dominansi tiap jalur pengamatan dan pengambilan sampel

Jumlah spesies kupu-kupu yang ditemukan pada tiga (3) jalur penelitian sebanyak 16 spesies dan 164 individu kupu-kupu yang termasuk dalam empat Famili yaitu Papilionidae, Nymphalidae, Pieridae, dan Lycaenidae. Kupu-kupu yang paling banyak ditemukan dalam penelitian ini dari famili 
Nymphalidae. Hal ini serupa dengan penelitian yang dilakukan oleh Juarni (2017) di Hutan Wisata Sesaot dari 13 spesies yang ditemukan, 6 spesies diantaranya berasal famili Nymphalidae. Hasil penelitian lain yang serupa yaitu penelitian yang dilakukan Iswahyuni (2010) di kawasan Hutan Jeruk Manis, Lombok Timur, dari 35 spesies yang ditemukan, 16 spesies diantaranya berasal dari famili Nymphalidae. Penelitian lain yang dilakukan oleh Ilhamdi et al. (2009) di Taman Wisata Alam Suranadi, ditemukan 28 spesies kupu-kupu, 11 spesies diantaranya berasal dari famili Nymphalidae.

Pada setiap lokasi penelitian famili Nympalidae ini paling banyak ditemukan karena kupu-kupu dari famili ini memiliki jumiah spesies terbesar dari famili lainnya. Famili ini terdiri dari sekitar 5.000 spesies yang tersebar diselunuh dunia. Kupu kupu ini bersifat polifag. Maksudnya kupukupu ini mempunyai jenis makanan lebih dari satu. Hal ini juga didukung dengan banyaknya tumbuhan yang bisa dijadikan sumber makanan sehingga famili ini sering dijumpai pada setiap lokasi penelitian.

Hasil penelitian menunjukan kupu-kupu yang ditemukan pada tiap jalur hampir berbeda, tergantung dari ketersediaan tanaman pakan dan tanaman inang dari kupu-kupu. Hal inilah yang menyebabkan kupu-kupu pada tiap jalur ada yang berbeda. Pada anggota family papilionidae, Papilio polytes ditemukan pada jalur air 1 dan jalur air 2 dikarenakan pada jalur tersebut tersedia tanaman inang dari spesies ini berupa citrus aurantifolia (jeruk nipis). Papilio demoleus juga ditemukan pada jalur 1 dikarenakan terdapat tanaman inang yang sama dengan papilio polytes yaitu jeruk nipis. Papilio Memnon hampir ditemukan pada setiap jalur, karena kupu-kupu ini sangat cepat beradaptasi dengan lingkungan apapun. Graphium Agamemnon ditemukan pada jalur 2 saja, dikarenakan pada jalur 2 terdapat tanaman inang berupa tanaman sirsak yang di tanam di sekitar perumahan warga.

Pada family nymphalidae, melanitis idea ditemukan pada jalur pinggir hutan, karena kupukupu ini senang hinggap di dedaunan kering. Sehingga apabila peneliti tidak terlalu jeli melihat keberadaan kupu-kupu ini tidak akan terlihat. Junonia athlites, spesies ini ditemukan pada jalur air 1 karena pada saat penelitian terdapat kacangkacangan pada suku leguminace dibantu penyerbukannya oleh kupu-kupu ini. Mycalensis
Horsfield ditemukan pada jalur air 1 dan jalur pinggir hutan, dikarenakan tipe habitatnya hamper sama. Spesies ini sangat menyukai tipe habitat yang bervegetasi semak. Hypolimnas bolina ditemukan pada jalur air 1 dan jalur pinggir hutan dikarenakan kupu-kupu ini menyukai terbang di sekitar aliran sungai dan mencari sumber makanan beruba buah buahan busuk di sekitar sungai. Elymnias hypemenstra, ditemukan pada jalur air 1 karena kupu-kupu ini senang hinggap di buah buahan yang busuk di sekitar jalur air 1. Sedangkan spesies neptis hylas dan ideopsis juventa hanya ditemukan di jalur pinggir hutan saja.

Pada family pieredae, kupu-kupu letopsia nina ditemukan pada seluruh jalur penelitian. Karena kupu-kupu ini sangat senang hinggap pada putri malu dan terdapat tanaman inang berupa bandotan. Catopsila pamona ditemukan pada jalur air 1 karena kupu-kupu ini sangat senang terbang di sekitar aliran sungai dan tempat yang terbuka dan terang. Eurema hecabe ditemukan pada tiap jalur penelitian. Karena kupu-kupu ini senang hinggap pada bunga-bunga kecil di dekat permukaan tanah. Dan eurema blanda, kupu-kupu ini hanya ditemukan pada jalur hutan karena menyukai hutan yang lembab dan dekat dengan sungai. Pada family lycanidae terdapat 1 spesies yaitu jamides bochus yang di temukan sedang menghisap bunga disekitar jalur air 1 .

Selain dari jumlah individu pada setiap jenisnya, keanekaragaman kupu-kupu juga dipengaruhi oleh kondisi lingkungan (Rodianti, 2014). Berdasarkan data hasil pengukuran faktor lingkungan menunjukkan suhu di Daerah Aliran Sungai (DAS) Taman Hutan Raya Sesaot berkisar antara suhu $24^{\circ} \mathrm{C}-25^{\circ} \mathrm{C}$ dengan suhu rata-rata yaitu sebesar $24,33^{\circ} \mathrm{C}$, sedangkan kelembaban udara berkisar antara $75 \%$ hingga $80 \%$ (Tabel 2). Kupukupu termasuk hewan poikeiloterm, dimana suhu tubuhnya dipengaruhi oleh suhu lingkungan. Kupukupu umumnya memerlukan suhu tubuh $25^{\circ} \mathrm{C}-41^{\circ} \mathrm{C}$ untuk melakukan aktifitasnya. Kupu-kupu akan berjemur (basking) sebelum terbang untuk memperoleh suhu tubuh optimal (Efendi, 2009). Umumnya kupu-kupu aktif pada hari yang cerah, hangat dan tenang, sekitar jam 9 pagi sampai jam 3 siang (Peggie dan Amir, 2006).

Indeks keanekaragaman jenis kupu-kupu pada jalur 1 dan jalur hutan tidak jauh berbeda. Hal ini dikarenakan kondisi lingkungan pada masingmasing lokasi hampir sama. Pada masing masing 
lokasi terdapat kawasan terbuka seperti semak, daerah hutan yang banyak celahnya dan tumbuhan yang sedang berbunga Umumnya vegetasi di dominasi oleh pohon mahoni switenia mahagoni dan perdu didominasi oleh Famili Zingiberaceae. Beberapa tumbuhan yang terdapat pada masingmasing lokasi misalnya: Ageratum conzoides, Impatiens balsamina, dan Baccaurea dulcis. Selain tumbuhan yang berbunga terdapat beberapa jenis paku-pakuan dan beberapa jenis pohon Selain itu juga terdapat kebun masyarakat, yaitu ubi kayu (Manihot utillisima), pisang (Musa paradisiaca), jambu biji (Psidium guajava), dan berbagai tanaman hias yang dapat mempengaruhi keberadaan kupukupu dilokasi tersebut.

\section{Kesimpulan}

Berdasarkan hasil penelitian diambil kesimpulan bahwa jumlah spesies kupu-kupu yang ditemukan pada tiga jalur penelitian sebanyak 16 spesies dan 164 individu kupu-kupu yang termasuk dalam empat Famili yaitu Papilionidae, Nymphalidae, Pieridae, dan Lycaenidae. Indeks keanekaragaman seluruh jenis kupu-kupu $\left(\mathrm{H}^{\prime}\right)$ di Daerah Aliran Sungai (DAS) Taman Hutan Raya Sesaot tergolong sedang yaitu 2,29.

\section{Ucapan Terima Kasih}

Penulis menyampaikan terima kasih kepada Balai KPH Rinjani Barat yang telah memberikan ijin untuk melakukan penelitian di dalam Kawasan TAHURA Sesaot, Dosen Pembimbing, Rekan-rekan pendidikan biologi 2017 (Yunisa, Suni dan Rifcka), dan segala pihak yang ikut berkontribusi dalam praktikum sampai terbit artikel ini.

\section{Referensi}

Ariani, L. (2013). Keanekaragaman dan Distribusi Jenis Kupu-kupu (Lepidoptera) di Kawasan Hutan Taman Wisata Alam Suranadi sebagai Media Pembelajaran Biologi. Skripsi. Universitas Mataram.

Borror, Donald. J., Charles, \& Normann (1992). Pengenalan Pelajaran Serangga. Yogyakarta: Gajah Mada University Press.
Darajati, W., Pratiwi, S \& Herwinda, E. (2016). Indonesian Biodiversity Strategy and Action Plan 2015-2020. Jakarta: Kementrian Perencanaan Pembangunan Nasional.

Efendi, M.A. (2009). Keragaman kupu-kupu (Lepidoptera: Dirtysia) di kawasan "hutan koridor" taman nasional gunung halimunsalak jawa barat. Tesis. Bogor: IPB.

Galudra, G., Buana, Y \& Khususiyah, N., (2010). Mau Melangkah ke Mana Pengelolaan Hutan Sesaot? Brief No. 09 Policy Analysis Unit. Bogor: World Agroforestry Center.

Ilhamdi, M. Liwa, Agil Al Idrus \& Didik Santoso (2019). Struktur Komunitas Kupu- Kupu di Taman Wisata Alam Suranadi, Lombok Barat. Jurnal Biologi Tropis. 19 (1), 147-153. https://doi.org/10.29303/jbt.v19i2.880

Iswahyuni, B.S. (2010). Keanekaragaman Jenis Kupu-kupu (Lepidoptera) di Kawasan Hutan Jeruk Manis Desa Kembang Kuning Lombok Timur. Skripsi. Universitas Mataram.

Juarni, Lalu Ahmad (2017). Studi Keanekaragaman Kupu-Kupu di Hutan Wisata Aik Berik dan Hutan Wisata Alam Sesaot Tahun 2017 (Skripsi). Mataram: UIN Mataram.

Magurran, A.E. (2004). Measuring Biological Diversity. Australia Blackwell Publishing Company.

Odum, E.P. (1993). Dasar-Dasar Ekologi. Tjahjono Samingan (penerjemah). Yogyakarta: Gadjah Mada University Press.

Peggie, D. \& Amir M. (2006). Panduan Praktis Kupu-kupu di Kebun Raya Bogor. Cibinong: Pusat Penelitian Biologi-LIPI.

Rodianti M, Yolanda R, \& Mubarrak J, (2014). Кири-Кири (Rhopalocera) Di Sekitar Kampus Universitas Pasir Pengaraian Kabupaten Rokan Hulu Provinsi Riau. Program Studi Pendidikan Biologi, Fakultas Keguruan Dan Ilmu Pendidikan, Universitas Pasir Pengaraian. 
Severns PM. (2008). Seeding population size and microhabitat association in Lupinus oreganus a threatened plant of western oregon grasslands. Nativeplants 9(3):358-364 https://doi.org/10.2979/NPJ.2008.9.3.358

Syaputra, M. (2015). Pengukuran Keanekaragaman Kupu-kupu (Lepidoptera) dengan Menggunakan Metode Time Search. Media Bina Ilmiah. 9(4): 68-72.

Tarumingkeng (2001). Serangga dan Lingkungan. Bogor: Institut Pertanian Bogor.

Wahyuni, T.E \& Fatahullah (2015). Panduan Lapangan Kupu-Kupu di TWA Kerandangan. Mataram: BKSDA NTB.

Zobar D, Genc H. (2008). Biology of the queen of spain fritillary, Issoria lathonia (Lepidoptera: Nymphalidae). Flor Entomol. 91: 237-240. https://doi.org/10.1653/00154040(2008)91[237:BOTQOS]2.0.CO;2 